\title{
Opportunities and challenges in using Learning Analytics in Learning Design
}

Citation for published version (APA):

Schmitz, M., Van Limbeek, E., Greller, W., Sloep, P., \& Drachsler, H. (2017). Opportunities and challenges in using Learning Analytics in Learning Design. In E. Lavoué, H. Drachsler, K. Verbert, J. Broisin, \& M. PérezSanagustín (Eds.), Data Driven Approaches in Digital Education. : 12th European Conference on Technology Enhanced Learning, EC-TEL 2017, Tallinn, Estonia, September 12-15, 2017, Proceedings (pp. 209-223).

Springer. Lecture Notes in Computer Science Vol. 10474 https://doi.org/10.1007/978-3-319-66610-5_16

DOI:

10.1007/978-3-319-66610-5_16

Document status and date:

Published: 01/09/2017

Document Version:

Peer reviewed version

Document license:

CC BY-SA

Please check the document version of this publication:

- A submitted manuscript is the version of the article upon submission and before peer-review. There can be important differences between the submitted version and the official published version of record. People interested in the research are advised to contact the author for the final version of the publication, or visit the DOI to the publisher's website.

- The final author version and the galley proof are versions of the publication after peer review.

- The final published version features the final layout of the paper including the volume, issue and page numbers.

Link to publication

\section{General rights}

Copyright and moral rights for the publications made accessible in the public portal are retained by the authors and/or other copyright owners and it is a condition of accessing publications that users recognise and abide by the legal requirements associated with these rights.

- Users may download and print one copy of any publication from the public portal for the purpose of private study or research.

- You may not further distribute the material or use it for any profit-making activity or commercial gain

- You may freely distribute the URL identifying the publication in the public portal.

If the publication is distributed under the terms of Article 25fa of the Dutch Copyright Act, indicated by the "Taverne" license above, please follow below link for the End User Agreement:

https://www.ou.nl/taverne-agreement

Take down policy

If you believe that this document breaches copyright please contact us at:

pure-support@ou.nl

providing details and we will investigate your claim.

Downloaded from https://research.ou.nl/ on date: 26 Apr. 2023 


\title{
Opportunities and challenges in using Learning Analytics in Learning Design
}

\author{
Marcel Schmitz ${ }^{1}$, Evelien van Limbeek ${ }^{1}$, Wolfgang Greller $^{2}$, Peter Sloep ${ }^{3}$ and Hendrik
} Drachsler ${ }^{3,4,5}$

${ }^{1}$ Zuyd University of Applied Sciences, Nieuw Eyckholt 300, 6419 AT Heerlen, NL

${ }_{2}^{2}$ Vienna University of Education, AT

${ }^{3}$ Open University, Valkenburgerweg 177, 6419 AT Heerlen, NL

${ }^{4}$ Goethe University Frankfurt, DE

${ }^{5}$ German Institute for International Educational Research (DIPF), DE

marcel.schmitz@zuyd.nl, evelien.vanlimbeek@zuyd.nl, wolfgang.greller@gmail.com, peter.sloep@ou.nl, hendrik.drachslerdou.nl.

\begin{abstract}
.
Educational institutions are designing, creating and evaluating courses to optimize learning outcomes for highly diverse student populations. Yet, most of the delivery is still monitored retrospectively with summative evaluation forms. Therefore, improvements to the course design are only implemented at the very end of a course, thus missing to benefit the current cohort. Teachers find it difficult to interpret and plan interventions just-in-time. In this context, Learning Analytics (LA) data streams gathered from 'authentic' student learning activities, may provide new opportunities to receive valuable information on the students' learning behaviors and could be utilised to adjust the learning design already "on the fly" during runtime. We presume that Learning Analytics applied within Learning Design (LD) and presented in a learning dashboard provide opportunities that can lead to more personalized learning experiences, if implemented thoughtfully.

In this paper, we describe opportunities and challenges for using LA in LD. We identify three key opportunities for using LA in LD: (O1) using on demand indicators for evidence based decisions on learning design; (O2) intervening during the run-time of a course; and, (O3) increasing student learning outcomes and satisfaction. In order to benefit from these opportunities, several challenges have to be overcome. We mapped the identified opportunities and challenges in a conceptual model that considers the interaction of LA in LD.
\end{abstract}

Keywords: Learning Design, Learning Analytics, Learning Dashboards, Metacognitive Competences, Feedback, Reflection

\section{Introduction}

Providing high quality education to students becomes increasingly challenging due to the high diversity of the student population that signs up for a study programme [1]. Due to the increasing demands for professionalization, as well as new competences and skills, lifelong learning has become more important than ever before [2, 3]. Higher 
education institutions (HEI) need to adapt to these changes and make their educational offers more open and flexible for students from heterogeneous backgrounds. This is challenging since different types of students enroll for a study course, such as students from secondary school with no previous work experience, students that aim for a career switch and combine their study with their job, or students that prefer to be educated in close relation to their workplace pursuing further professionalization in their current practice $[4,5]$. Therefore, HEI study programmes need to take the individual needs and life situation of their learners into account and provide better customized educational possibilities. Traditional HEI struggle with fulfilling this mission which resulted in a huge variety of commercial providers such as Coursera and edX aiming to fill the gap with open and flexible educational offers such as online courseware that often is open or designed for the masses (i.e. MOOCs). Recently, more and more traditional universities in the Netherlands have adjusted their educational models towards these needs, where strong investments have been made in flexible and personalized educational offers [6]. One result of this is that many traditional and applied sciences universities extend their education with more malleable and distance education offers. Among changing and adjusting the educational model also technology innovations are explored that can foster these new requirements. Among various technologies to facilitate blended and distance learning models, Learning Analytics (LA) has been identified as a most promising technology to aid the personalization of learning and also change the educational model or even a course design due to insights gained from data. FitzGerald et al. [48] illustrate the different important dimensions to take into consideration for personalization of technology enhanced learning. In terms of this framework, using LA in LD tends to provide a cognitive-based and whole-person personalization.

In the rise of LA globally and in the Netherlands specifically, several ways to gather 'authentic' data regarding student learning behavior are being used; institutions use electronic learning environments, digital assessment methods, and student information systems to track student learning processes and behaviors. Furthermore, digital devices like mobile phones, tablets and laptops are being used to collect activities of students. It is this insight into the students' learning processes and behaviors that, when presented in a user-friendly way, could enable teachers to adapt their course and learning activities "on the fly", during the course's run-time. Additionally, these data could provide students with insight into their own learning behavior in comparison with the course goals, achievements or the performance of their fellow students. This could - if guided properly and if the student is able to reflect and act on the information using metacognitive competences [7] - enable them to adapt their learning behavior to become more effective or efficient.

In this paper, we identify and present three main opportunities for using LA in LD, with nine sub-opportunities and six sub-challenges based on the main opportunities, by critically studying current scientific literature on LA, LD, learning dashboards and meta-cognitive competences. These will be presented in table format and discussed in the sections below. 


\section{Identifying opportunities and challenges for LD and LA}

In order to find and extrapolate the main opportunities for using Learning Analytics in Learning Design, we thoroughly and comprehensively analysed the current scientific literature on LA, LD, learning dashboards and meta-cognitive competences. In table 1 and the remainder of this article, those opportunities and challenges are presented and marked with identifiers such as 'O+Number' for the opportunities, 'SO+Number' for sub-opportunities and 'SC+Number' for the sub-challenges. If an opportunity or challenge is linked to a key opportunity in the text, the identifier is concatenated, for example O1.SC2. is sub-challenge number 2 related to opportunity 1.

\begin{tabular}{|c|c|c|c|c|c|}
\hline & $\begin{array}{c}\text { Learning } \\
\text { Design }\end{array}$ & $\begin{array}{l}\text { Learning } \\
\text { Analytics }\end{array}$ & $\begin{array}{c}\text { Learning } \\
\text { Dashboards }\end{array}$ & \begin{tabular}{|c|} 
Metacognitive \\
Competences
\end{tabular} & References \\
\hline Ol. Using on demand indicators for evidence based decisions on LD & $\mathrm{x}$ & $\mathrm{x}$ & $\mathrm{x}$ & & 19 \\
\hline SOl. Observing the effects of LD & $\mathrm{x}$ & $\mathrm{x}$ & & & 18,33 \\
\hline SO2. Sharing knowledge on LD & $\mathrm{x}$ & & $\mathrm{x}$ & & 18,33 \\
\hline SO3. Involving the students & $\mathrm{x}$ & & $\mathrm{x}$ & & 18,33 \\
\hline SCl. Interoperability of $L D$ & $\mathrm{x}$ & & & & 14,46 \\
\hline SC2. Interoperability of LA & & $\mathrm{x}$ & & & $34,35,46$ \\
\hline 02. Intervening during the run-time of a course & $\mathrm{x}$ & $\mathrm{x}$ & $\mathrm{x}$ & $\mathrm{x}$ & 18,33 \\
\hline SOl. Delivering information/feedback on demand & & $\mathrm{x}$ & $\mathrm{x}$ & & 18,33 \\
\hline SO2. Creating and using interventions & $\mathrm{x}$ & $\mathrm{x}$ & $\mathrm{x}$ & $\mathrm{x}$ & $27,30,32,35$ \\
\hline SO3. Changing learning behavior & $\mathrm{x}$ & $\mathrm{x}$ & $\mathrm{x}$ & $\mathrm{x}$ & $31,32,35$ \\
\hline SCl. Presenting relevant information the right way & $\mathrm{x}$ & $\mathrm{x}$ & $\mathrm{x}$ & & 35 \\
\hline SC2. Improving ability to act on information & & & & $\mathrm{x}$ & 30,56 \\
\hline 03. Increasing student learning outcome and satisfaction & $\mathrm{x}$ & $\mathrm{x}$ & $\mathrm{x}$ & $\mathrm{x}$ & $31,34,35$ \\
\hline SOl. Making learning outcomes visible & $\mathrm{x}$ & & $\mathrm{x}$ & & 53,55 \\
\hline SO2. Making learning information accesible & $\mathrm{x}$ & $\mathrm{x}$ & $\mathrm{x}$ & & 52,56 \\
\hline SO3. Improving learning to learn & $\mathrm{x}$ & $\mathrm{x}$ & $\mathrm{x}$ & $\mathrm{x}$ & 54,55 \\
\hline SCl. Understanding learning dashboards & & & $\mathrm{x}$ & $\mathrm{x}$ & 47 \\
\hline SC2. Coping with the diversity of students & $\mathrm{x}$ & $\mathrm{x}$ & $\mathrm{x}$ & $\mathrm{x}$ & $1,4-6$ \\
\hline References & $8-10,13-16$ & $18,19,23-29,31,32$ & $18,31-35$ & $7,11,35$ & \\
\hline References aligning $L A$ and $L D$ & \multicolumn{2}{|c|}{$40,42,44,45,46,47$} & & & \\
\hline
\end{tabular}

Table 1. Overview opportunities and challenges of LA for LD.

\subsection{Learning Design.}

To define LD it is necessary to understand the definition of a learning activity. In this research, a learning activity is seen as a task that a student can do that involves interaction with teachers, fellow students, or content items in order to increase their knowledge. The LD is the description of all elements of the course's design in such a way that teachers can understand it and can use it. Elements of LD are the description of the learning activities that students have to do, the resources needed and the support actions a teacher can provide to facilitate the learning process [8]. Teachers can use help in the evaluation of the design and in the revision of courses. This is currently methodologically done by formative assessment during the course, but mostly by 
summative assessments and qualitative surveys at the end of the course as instructional design models like ADDIE propose [9]. This brings us directly to our main opportunities for LA supported LD: O1. Using on demand indicators for evidence based decisions on learning design by using authentic data of student behavior. In parallel, these, on demand insights in data on student behavior create possibilities for teachers to make alterations in the LD of the current course and for students to adjust their learning behavior. We call this second opportunity: O2. Intervening during the run-time of a course.

Although there have been standardization approaches for communication of LD like IMS-LD[51], these are seldom implemented in educational practices. Therefore, a common widely accepted language to discuss LD within education is currently lacking. The same holds for frameworks regarding the use and evaluation of LDs [10, 13-16]. They often differ in their approaches. For instance, a framework that is using LORI, a tool for eliciting learning object evaluations, has nine different aspects like: content quality, learning goal alignment, motivation, presentation, each individually based on several theories from different researchers, while Baker [10] presents a framework based on Bloom's Taxonomy [11] and Tyler's Basic Principles [12]. Another approach is chosen by Bundsgaard and Hansen, who claim to combine several frameworks into a holistic view where learning potential plays a big role [13]. Falconer et al. [14] illustrate the diversity by presenting an overview of LD frameworks that focus on either: "stages of a learning cycle; degree of embeddedness of information on LD; representation, medium and format; mode of use based on Laurillard's conversational model; and degree of adaptation." Considering this plethora of approaches and available standards for LD leads us to our first challenge, which is the absence of a commonly accepted language in which learning activities based on different LD frameworks can be discussed O1.SC1 Interoperability of LD.

LD is not a static field. As HEI are trying to facilitate different target groups with their education, changes for the LD are demanded. Examples of relative new target groups for traditional universities are workers, the unemployed and part-time students that are subjects in projects developing innovative LD's. As the group of students is becoming more diverse by these efforts, the challenge O3.SC2. Coping with the diversity of students becomes something to take into consideration when developing education.

\subsection{Learning Analytics.}

Over the last years, sources to collect data in the context of learning are becoming increasingly available, which leads to large amounts of learning data [17]. The availability and accessibility of data that learners produce during learning activities is an additional identification of the learning behavior of a student and could be of great value regarding feedback and evaluation of courses and consequently has potential for the (re)design of learning activities. LA describes all aspects of collecting, cleaning, analyzing and visualizing this data. The use of LA to inform decision-making in education is not new, predecessors of LA have been used to inform students in choosing study programs, curriculum development, design of learning outcomes, get insight into 
behavior of students and their learning process, personalize learning, improve instructor performance, acquire insight in employment opportunities after graduation, and enhance research [18]. But the scope and scale of its potential has increased enormously with the rapid adoption of technology over the last few years and the dependent growth of tracking data that comes with the use of technology. We are now at a stage where data can be automatically harvested, and analysis of these data opens up the opportunity for transforming learning insights into learner abilities and patterns of behavior, cognition, motivation, and emotions [19], and, therefore, studying the effects of design choices within higher education. We identify this as a sub-opportunity: O1.SO1. Observing effects of $\mathrm{LD}$.

Frameworks for LA are used to bring structure to all relevant topics [20 - 23, 26]. A diverse selection of frameworks can be found, varying from Open Learning Analytics [20] to a framework on characteristics of LA [21] and a framework of quality indicators for LA $[22,50]$. The differences between the frameworks and the dedicated work that each framework is based on delivers a large amount of research, but makes it difficult to talk about LA on one level between all stakeholders. We call this challenge O1.SC2. Interoperability of LA. A comprehensive introduction to different domains that are affected by LA was provided by Greller and Drachsler [23]. They developed a generic design framework that can serve as a guide in developing LA applications in support of educational practice. The framework addresses six fields of attention that have to be addressed in every LA design: 1 . Stakeholders, 2. Objectives, 3. Data, 4. Instruments, 5. External constraints, 6. Internal limitations. For the implementation of LA it is very important to make all stakeholders aware of the aspects of LA and find a common understanding to communicate LA findings. Organizations struggle with the complexity of the field of LA. Considering the five step LA sophistication model developed by the Society of Learning Analytics Research (SoLAR) [19], there is still a lot of work to be done in order to transform the educational sector to a data-driven educational science. Most organizations in Europe are still on level one (Aware) of the sophistication model and only very few more advanced organizations are heading towards levels two (Experimentation) and three (Institution wide use). In the various LA reviews [18, 19, 24], there is little mention about experiences of using LA supported LD in educational practice. Despite the great potential surrounding LA, most attempts to implement LA strategies in educational organizations are still at the initiation phase $[25,26]$.

Rienties and Toetenel [27] state that the challenge in the field of LA is how to put the power of LA into the hands of teachers so that they are able to use it and act upon it. Although an increasing body of literature has become available regarding how researchers and institutions have experimented with interventions using LA [28, 29] and first steps of a conceptual model (Analytics4Action) [30] are made, no comprehensive conceptual model, nested within a strong evidence-base, is available that describes how teachers and administrators can use LA to make successful interventions in their own educational practice. We define this challenge as: O2.SC2. Improving ability to act on information, and believe that more research into the use of Learning Dashboard as part of the LD would provide some opportunities to overcome this challenge. 


\subsection{Learning dashboards.}

A dashboard can be defined as a visual display of the most important information needed to achieve one or more objectives; consolidated and arranged on a single screen so the information can be monitored at a glance [31]. A learning dashboard can provide both teachers and students with insights into study progress and potential for improvement. Learning dashboards give opportunities for awareness, reflection, sense making, recommendations, and, therefore, could improve learning by helping users raising their ability to act on information [32]. From a teacher perspective we call this opportunity O2.SO2. Creating and using interventions, while from a student perspective, we derive the opportunity 02.SO3. Changing learning behavior. Presenting learning data in the context of LD provides the opportunity O1.SO2 Sharing knowledge on LD. Insight in which design choices work and which don't in comparable contexts enables institutions to increase educational quality and help to grasp the opportunity of O1. Using on demand indicators for evidence based decisions on learning design [18, 33].

A diversity of learning dashboards have been reviewed in several studies $[34,35]$. In the review of Bodily and Verbert [34], the most mentioned goal for developing a learning dashboard for the student is creating awareness and reflection on their learning process (37\% out of 94 articles). Awareness and reflection of their educational process leads to two opportunities: first the opportunity of O3.SO2 Making learning information accessible as reflection amplifiers for self-directed learners, or: as benchmarking of student progress against others, which can also be used by teachers if it is in actionable format [52], second the opportunity of O1.SO3. Involving the students in the educational process. The recommendation of resources was the second highest goal (29\% out of 94 articles). This review mentions that $19 \%$ of the articles state that the improvement of retention or engagement is the main goal for implementing a learning dashboard. All these goals contribute to an opportunity we named O3. Increasing student learning outcome and satisfaction. Bodily and Verbert show how articles did report on effects of using learning dashboards with regard to the effect of using the dashboard on student behavior (15 out of 94), student skills (14 out of 94) or student achievement ( 2 out of 94). These elements of the review illustrate that learning dashboards are developed for different goals from different perspectives and it also illustrates that there is an opportunity to improve students' learning outcomes, satisfaction (O3.), and behavior (O2.SO3.). Bodily and Verbert conclude that more research is needed on the actual effects of these reporting systems on student behavior, student achievement and skills.

Schwendimann, Rodriguez-Triana, Vozniuk, Prieto, Boroujeni, Holzer, Gillet, and Dillenbourg [35], present an overview of the state of the art of learning dashboards. They reviewed 53 papers and identified more than 200 indicator types, divided them into the categories: learner, action, content, result, context and socially related. This many indicator types that can be used in analyses mean an enormous potential of LA. It is great to see that there are plenty of indicators for LA, but it is a challenge to select the right indicators for a specific learning activity to provide meaningful insights into the learning process. This requires a lot of knowledge about LA also at the side of the 
teacher to select and use the right indicators. For us, this is part of a challenge we named O2.SC1. Presentation of relevant information the right way. The review of Schwendimann et al. also showed that, research on the effects of learning dashboards is still young, demonstrated by the considerable amount of exploratory work and limited number of proof-of-concept studies that were rarely implemented (and evaluated) in educational practice. Most of the 53 articles Schwendimann researched describe future work and open issues as repeating their research on different targets (students instead of teachers and vice versa) and they also address more usability research in educational practice. The granularity, visualization and interpretation of the information are mentioned as important issues in that type of research.

One of the mentioned goals for using learning dashboards are increasing student learning outcomes. Traditional HEI in the Netherlands are using learning outcomes as a starting point while rethinking LD to reach other target groups [6]. O3.SO1. Making learning outcomes visible $[53,55]$ is an opportunity applied within these new LDs to be able to create workplace related education, where competences can be proved by a portfolio of work related products or enable students to choose their own learning path. Either option improves student's learning outcome and satisfaction (O3.).

\subsection{Metacognitive competences used in $\mathrm{LD}$ and $\mathrm{LA}$}

Park and Jo [47] found that students' overall satisfaction on learning dashboards is correlated with both the degree of understanding and students' capability to change their behavior. This presents the challenge of building a learning dashboard in a way that is understandable for users, which we called O3.SC1. Understanding learning dashboards. In order to achieve this, supporting attributes have to be added in such a way that the metacognitive competences of students and teachers are enforced so that they are able to understand and interpret the information, and be able to act on it (O2.SO1, O2.SO2. and O2.SO3.). Most recently, Jivet et al.[49] conducted a study on pitfalls for LA dashboards and showed that most dashboards only consider the reflection process very roughly They conclude that they are not properly designed to meet the needs of their actual users; the teacher and learners.

A definition of metacognitive knowledge is given by Flavell [7]: "metacognitive knowledge consists primarily of knowledge or beliefs about what factors or variables act and interact in what ways to affect the course and outcome of cognitive enterprises". In the context of this research, cognitive experiences are understood as learning experiences. Awareness and interpretation of the information presented from learning experiences and critical thinking on actions and behavior that can be applied on the elements of the learning experience are metacognitive competences. These are competences needed to think of factors necessary to act adequately on the information provided [23]. Awareness, however, is not the only aspect that influences the process of feedback, reflection and behavioral change, i.e. of self-efficacy and self-regulated learning [36]. Winne [37] describes self-regulated learning as "principally comprised of knowledge, beliefs, and learned skills, malleable in response to environmental influences" and as something that learners inherently do. Zimmerman [38] adds to this that self-regulated learning is indeed about more than knowledge and skills and that 
metacognitive competences are also influenced by emotions, one's behavior and one's social environment play an important role. Learners thus have different ways to construct knowledge and they have different ways to think about how that construction took place on the basis of the information given to them when learning in a selfregulated way [39]. Learners can act and react in different ways based on that information.

So not only, a clear and user-friendly presentation of the LA information is a challenge (O2.SC1.Understanding learning dashboards), but it also is a challenge to train and use the metacognitive competences of teachers and students. We identified this as challenge O2.SC2. Improving ability to act on information so that they are able to make use of the information and act directly on the information they are provided with.This challenge is seldomly addressed in research practice of learning dashboards, just 3 of the 53 articles reviewed by Schwendimann et al. [35] talk about competences or how to enforce them. We believe that acquisition of knowledge and skills on using LA in practice will be key for the uptake of LA. Doing so will enable us to use the opportunity O3.SO3. Improving learning to learn.

\section{Aligning LA and LD in frameworks and dashboards}

The potential value of using LA as a purposeful element in the LD of modules, is described by several researchers $[40,41,42]$. In developing a $\mathrm{LD}$, a teacher or educational designer works on all phases of an instruction; starting from the definition of prior knowledge prerequisites of the target student group, the learning objectives and outcomes, and the design of assessments to test if the outcomes have been achieved. In between are many choices for appropriate learning activities and sequences, content, teaching methods, materials and other resources that contribute to achieving the learning objectives of the design. The teaching activities and resources are provided increasingly over IT infrastructures and are most of the time also digitally available. This offers the possibility to use LA as part of the learning environment and the LD $[27,40]$.

The alignment of LA and LD changes the design-process of learning activities from a post-evaluation design process into a permanent monitoring design process. In this way, teachers should already consider measurements at the design phase of their learning activities and they should select most suitable LA indicators that can be used to monitor if the selected learning activities of a course are going as intended or not. But the alignment also changes the monitoring process of courses into a learning design-aware monitoring process. It is of crucial importance for a LA supported LD to consider potential LA indicators already while designing the learning objectives and related activities [40]. Like assessment procedures, LA indicators should be considered in the very beginning of the development of the LD. In that way, e.g. a 'forum discussion' is not only an effective learning activity by itself, but LA can also provide a much more efficient and effective overview of e.g. student participation through social network analysis tools [41] that can provide students with self-monitoring information and make teachers more aware of the learning process of their students and 
adds possibilities for personalized feedback. Using LA while scripting LD and thinking about LD when initializing LA indicators makes it necessary to use a more unified way of talking and thinking about LD (O1.SC1.) and LA (O1.SC2.). By collecting data from learners on learning activities in a LA dashboard that is designed according to LD intentions will enable teachers and educational designers to make improvements to their courses during run-time (O2.) [42]. Only few studies on the alignment of LA and LD have been done. Wise et al. [43] sums up a list of studies that "underscore the idea that the use of a combined approach of $L D$, teacher inquiry into student learning and LA can produce effective new pedagogies" [43]. Rodriguez et al. [44] are trying to combine scripting and monitoring and vice versa. To take advantage of this potential, teachers and instructional designers need to keep LA in mind while designing learning activities and the LD together to select the most appropriate LA indicators for the dashboard solution [44]. Rienties et al [30] are developing a framework to enable teachers to create interventions by using LA for LD. All frameworks that incorporate LA and LD [10, 14, $15,30,45,46]$ describe roughly three elements: resources, learning tasks and supporting mechanisms that can be monitored in learning contexts. Each framework mentions some type of timing where the monitoring takes place. This can be during a course, after a course and after several courses. The conceptual framework of Bakhari et al. [45] describes this timing item as a temporal analysis, which makes a distinction in the frequency of the analysis event: recurring events (weekly workspace meeting), submission events (assignments), single events (guest lectures). Timing is an opportunity we called O2.SO1. Delivering information/feedback on demand. Further work needs to be done to create frameworks and tools and research the effect of using them to establish an evidence base.

\section{Conclusion}

In this paper, we presented several opportunities and challenges for aligning and incorporating LA into LD to innovate and improve higher education and achieve a more personalized and "just-in-time" learning culture with more on demand feedback mechanisms. In figure 1, below, a tentative model for the implementation of LA supported LD is shown. It maps the identified opportunities and challenges from this study to the model. 


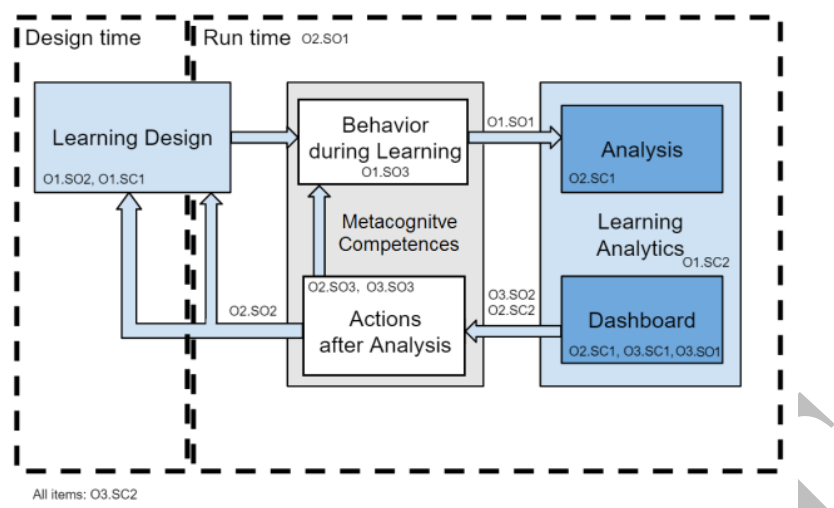

Fig. 1. Proposed LA in LD model, including opportunities and challenges of table 1.

From a course design perspective, LA can be used to take the measurement of quality of learning activities into consideration which delivers the opportunity O1.SO1 Observing the effects of LD. Collecting this knowledge enables users to use opportunity O1.SO2. Sharing knowledge on LD so that the design can be improved and made more efficient, effective and reusable. Two challenges here are O1.SC1. Interoperability of LD and O1.SC2. Interoperability of LA. Because of the large amount of frameworks and tools for both LD and LA, some type of order is necessary to be able to cooperate in designing learning activities with colleagues and to be successful with opportunity O1.SO3. Involving students. The observations, the possibility to share knowledge, the learner centered way of involving the students and the coping with the challenges of interoperability of LD and LA make it possible to build a base for future research and thereby addressing the key opportunity O1. Using on demand indicators for evidence based decisions on learning design Steps are made on this subject with the development of frameworks, but practical research is needed. When striving for more personalized education, evidence based choices on which learning activities are most fit for an individual student are essential for educational designers.

From a user perspective, LA for LD creates the opportunity O2.SO1. Delivering information/feedback on demand. For teachers this means getting timely feedback on the effects of decision in de LD which makes it possible to seize the opportunity of O2.SO2. Creating and using interventions to help students. For students this means receiving feedback and personal support from teachers and the opportunity to O2.SO3. Change learning behavior with regard to the course. Neither teachers nor students are able to do this without a visualization that adresses the challenge O2.SC1. Presenting the relevant information the right way. Furthermore, teachers and students should be able to view, interpret and act based on the information they have received. In our opinion, the biggest challenge is O2.SC2. Improving the ability to act on information. Some research mentions addressing metacognitive competences to tackle this challenge, but very little has been done in this field, which therefore provides opportunities for further research. If teachers and students are trained and facilitated in using their metacognitive competences to not only understand the relevant information 
delivered to them on demand, but to also change their behavior or use interventions accordingly, then the main opportunity 02. Intervening during the run-time of a course can become a reality. But as Jivet et al. [49] laid out in a recent study, this objective is only seldom reached and, therefore the LA Dashboard applications often fail in supporting the students and teachers in the way that is intended. An instrument that delivers on demand information enabled experiences of adaptations of the learning experiences and thereby an effect of improved personalization.

From an HEI perspective, O3.SO1. Making learning outcomes visible creates an opportunity to change the educational process and make it attainable for new target groups. This automatically presents the challenge of O3.SC2. Coping with the diversity of students that higher education institutions are confronted with. Tools like learning dashboards enable O3.SO2. Making learning information accessible by using reflection amplifiers for self-directed learners, or as benchmarking of student progress. Both elements improve personalized self-regulated learning and regulatory teaching. Bringing well-designed user-friendly learning dashboards (O3.SC1. Understanding learning dashboards), as instruments for application of LA in LD, into the playing field and enabling both students and teachers is using these information by increasing meta-cognitive competences, would add to the opportunity O3.SO3. Improving learning to learn, . We believe that if students and teachers are enabled and facilitated to understand the data that is brought to them and are motivated to act on their learning process or learning design, HEI's are a step closer todelivering personalized content and processes enforced by LA in LD. Only then the key opportunity of $\mathbf{O}$.3. Increasing student learning outcome and satisfaction becomes achievable.

In the upcoming future, and following on from this model, we want to further investigate how LA supported LD can be implemented in authentic teaching situations. Key for this implementation will be the empowerment of teachers and learners with metacognitive competences to directly think along LA indicators for the use in their LD and interaction with their students. Part of this future investigation is whether our suggested solution affects the described opportunities and challenges with the aim of making education more personalized.

A first attempt towards the practical part of this research is currently conducted in the REFLECTOR project that is funded by the SURF foundation in the Netherlands. Within the REFLECTOR project we are mainly focusing on the following opportunities and challenges: 01.SO1, 01.SO3, O2.SO1, O2.SC2, O3.SO1, O3.SO2, O3.SC1. We are designing and implementing a learning analytics dashboard into a ICT-course design in close colaboration with the end users. We will address teachers ${ }^{\text {* }}$ as well as students'needs related to their capability to reflect and act upon their teaching and learning behaviour. To study whether the teachers followed their intended learning design and students their planned study behaviour, teachers will be interviewed about the intended learning design of the course and argumentation for their learning activities. We will also survey students' intended study behavior within the particular course by using a Dutch version of the MSLQ [57]. Both students' and teacher behavior will nbe monitored during the course runtime to study the effects of ondemand feedback provided from the learning analytics dashboard on the intended 
teaching or learning behavior. by.

\section{Acknowledgements}

We would like to thank the SURF Foundation \& NRO for supporting the efforts of Marcel Schmitz, Evelien van Limbeek and Hendrik Drachsler under the REFLECTOR project grant.

\section{References}

1. Altbach, P., Reisberg, L., Rumbley, L.: Tracking a global academic revolution. Change 42(2), 30-39 (2010).

2. Field, J.: Lifelong learning and the multigenerational workforce. In: The multi-generational and aging workforce: challenges and opportunities, pp 311-325. Edward Elgar Publishing, Cheltenham (2015).

3. Volles, N.: Lifelong learning in the EU: changing conceptualisations, actors, and policies. Studies in Higher Education 41(2), 343-363 (2014).

4. Nonis, S., Hudson, G.: Academic performance of college students: influence of time spent studying and working. Journal of Education for Business 81(3), 151-159 (2006).

5. Tuononen, T., Parpala, A., Mattsson, M., Lindblom-Ylänne, S,: Work experience in relation to study pace and thesis grade: investigating the mediating role of student learning. Higher Education 72(1), 41-58 (2016).

6. Ministerie van Onderwijs, Cultuur \& Wetenschap: De waarde(n) van weten: strategische agenda hoger onderwijs en onderzoek 2015-2025. Den Haag (2015).

7. Flavell, J.: Metacognition and cognitive monitoring: a new area of cognitive-developmental inquiry. American Psychologist 34(10), 906-911 (1979).

8. Donald, C., Blake, A., Girault, I., Datt, A., Ramsay, E.: Approaches to learning design: past the head and the hands to the HEART of the matter. Distance Education 30(2), 179-199 (2009).

9. Peterson, C.: Bringing ADDIE to life: instructional design at its best. Journal of Educational Multimedia and Hypermedia 12(3), 227-241 (2003).

10. Baker, R.: A framework for design and evaluation of internet-based distance learning courses: Phase one-Framework justification design and evaluation. Online Journal of Distance Learning Administration 6(2), 43-51 (2003).

11. Bloom, B., Engelhart, M., Furst, E., Hill, W., Krathwohl, D.: Taxonomy of educational objectives: the classification of educational goals. Handbook I: cognitive domain. David McKay Company, New York (1956).

12. Tyler, R.: Basic principles of curriculum and instruction. University of Chicago Press, Chicago (1949).

13. Bundsgaard, J., Hansen, T.: Evaluation of learning materials: a holistic framework. Journal of Learning Design 4(4), 31-45 (2011).

14. Falconer, I., Beetham, H., Oliver, R., Littlejohn, A.: Mod4L final report: representing learning designs. Final report for the JISC-funded MOD4L project. Glasgow (2007).

15. Leacock, T., Nesbit, J.: A framework for evaluating the quality of multimedia learning resources. Educational Technology \& Society 10, 44-59 (2007).

16. Falconer, I.: Mediating between practitioner and developer communities: the learning activity design in education experience. Alt-J 15(2),155-170 (2007). 
17. Masie, E.: Big learning data. ASTD Press, Alexandria (2014).

18. Avella, J., Kebritchi, M., Nunn, S., Kanai, T.: Learning analytics methods, benefits, and challenges in higher education: a systematic literature review. Online Learning Journal 20(2), 13-29 (2016).

19. Siemens, G.: Learning analytics: the emergence of a discipline. American Behavioral Scientist 57(10), 1380-1400 (2013).

20. Siemens, G., Gasevic, D., Haythornthwaite, C., Dawson, S., Shum, S., Ferguson, R., Duval, E., Verbert, K., Baker, R.: Open learning analytics: an integrated \& modularized platform. (2011).

21. Cooper, A.: A framework of characteristics for analytics. CETIS Analytics Series 1(7), 117 (2012).

22. Scheffel, M., Drachsler, H., Stoyanov, S., Specht, M.: Quality indicators for learning analytics. Educational Technology \& Society 17(4), 124-40 (2014).

23. Greller, W., Drachsler, H.: Translating learning into numbers: a generic framework for learning analytics. Educational Technology \& Society 15(3), 42-57 (2012).

24. Ferguson, R.: Learning analytics: drivers, developments and challenges. International Journal of Technology Enhanced Learning 4(5/6), 304-317 (2012).

25. Bichsel, J.: Analytics in higher education: benefits, barriers, progress, and recommendations. Educause Center for Applied Research, Louisville (2012).

26. Colvin, C., Rogers, T., Wade, A., Dawson, S. Gasevic, D., Shum, S., Nelson, K., Alexander, S., Lockyer, L., Kennedy, G., Corrin, L., Fisher, J.: Student retention and learning analytics: a snapshot of Australian practices and a framework for advancement. (2015).

27. Rienties, B., Toetenel, L.: The impact of 151 learning designs on student satisfaction and performance: social learning (analytics) matters. In: Proceedings of LAK16 6th International Conference on Analytics and Knowledge, pp 339-343. (2016).

28. Clow, D., Cross, S., Ferguson, R.: Evidence hub review. (2014).

29. Papamitsiou, Z., Economides, A.: Learning analytics and educational data mining in practice: a systematic literature review of empirical evidence. Educational Technology \& Society 17(4), 49-64 (2014).

30. Rienties, B., Boroowa, A., Cross, S., Kubiak, C., Mayles, K., Murphy, S.: Analytics4Action evaluation framework: a review of evidence-based learning analytics interventions at the Open University UK. Journal of Interactive Media in Education (1), 2 (2016).

31. Few, S, Information dashboard design: the effective visual communication of data. O'Reilly Media, Sebastopol (2006).

32. Verbert, K., Duval, E., Klerkx, J., Govaerts, S., Santos, J.: Learning analytics dashboard applications. American Behavioral Scientist 57(10), 1500-1509 (2013).

33. Mor, Y., Ferguson, R., Wasson, B.: Editorial: learning design, teacher inquiry into student learning and learning analytics: a call for action. British Journal of Educational Technology 46(2), 221-229 (2015).

34. Bodily, R., Verbert, K.: Trends and issues in student-facing learning analytics reporting systems research. In: Proceedings of the Seventh International Learning Analytics \& Knowledge Conference, pp 309-318. ACM, New York (2017).

35. Schwendimann, B., Rodriguez-Triana, M., Vozniuk, A., Prieto, L., Boroujeni, M., Holzer, A., Gillet, D., Dillenbourg, P.: Perceiving learning at a glance: a systematic literature review of learning dashboard research. IEEE Transactions on Learning Technologies 10(1), 30-41 (2017).

36. Butler, D., Winne, P.: Feedback and self-regulated learning: a theoretical synthesis. Review of Educational Research 65(3), 245-281 (1995). 
37. Winne, P.: Inherent details in self-regulated learning. Educational Psychologist 30(4), 173187 (1995).

38. Zimmerman, B.: Self-regulation involves more than metacognition: a social cognitive perspective. Educational Psychologist 30(4), 217-221 (1995).

39. Winne, P.: How software technologies can improve research on learning and bolster school reform. Educational Psychologist 41(1), 5-17 (2006).

40. Lockyer, L., Heathcote, E., Dawson, S.: Informing pedagogical action: aligning learning analytics with learning design. American Behavioral Scientist 57(10), 1439-1459 (2013).

41. Bakharia, A., Dawson, S.: SNAPP: a bird's-eye view of temporal participant interaction. In: Proceedings of LAK11 1th International Conference on Analytics and Knowledge, pp 168173. (2011)

42. Persico, D., Pozzi, F.: Informing learning design with learning analytics to improve teacher inquiry. British Journal of Educational Technology 46(2), 230-248 (2015).

43. Wise, A., Shaffer, D.: Why theory matters more than ever in the age of big data. Journal of Learning Analytics 2(2), 5-13 (2015).

44. Rodríguez-Triana, M., Martínez-Monés, A., Asensio-Pérez, J., Dimitriadis, Y.: Scripting and monitoring meet each other: aligning learning analytics and learning design to support teachers in orchestrating CSCL situations. British Journal of Educational Technology 46(2), 330-343 (2015).

45. Bakharia, A., Corrin, L., Barba, P. De, Kennedy, G., Gasevic, D., Mulder, R., Williams, D., Dawson, S., Lockyer, L.: A conceptual framework linking learning design with learning analytics. In: Proceedings of LAK16 6th International Conference on Analytics and Knowledge, pp 329-338. (2016).

46. Verbert, K., Govaerts, S., Duval, E., Santos, J., Van Assche, F., Parra, G., Klerkx, J.: Learning dashboards: an overview and future research opportunities. Personal and Ubiquitous Computing 18(6), 1499-1514 (2014).

47. Park, Y., Jo, I.: Development of the learning analytics dashboard to support students' learning performance. Journal of Universal Computer Science 21(1), 110-133 (2015).

48. FitzGerald, E., Kucirkova, N., Jones, A., Cross, S., Ferguson, R., Herodotou, C., Hillaire, G., Scanlon, E.: Dimensions of personalisation in technology-enhanced learning: a framework and implications for design. British Journal of Educational Technology (2017).

49. Jivet, I., Scheffel, M., Drachsler, H., Specht, M.: Awareness is not enough: pitfalls of learning analytics dashboards in the educational practice. In: Proceedings of the 12th European Conference on Technology Enhanced Learning (EC-TEL 2017) (in press).

50. Scheffel, M., Drachsler, H., Toisoul, C., Ternier, S., Specht, M.: The proof of the pudding: examining validity and reliability of the evaluation framework for learning analytics. In: Proceedings of the 12th European Conference on Technology Enhanced Learning (EC-TEL 2017) (in press).

51. Koper, R., Olivier, B.: Representing the learning design of units of learning. Educational Technology \& Society 7(3), 97-111 (2004).

52. Prinsloo, P., Slade, S.: An elephant in the learning analytics room: the obligation to act. In: LAK '17 Proceedings of the Seventh International Learning Analytics \& Knowledge Conference, pp 46-55. (2017).

53. Trigwell, K., Prosser, M.: Improving the quality of student learning: the influence of learning context and student approaches to learning on learning outcomes. Higher Education 22(3), 251-266 (1991).

54. De La Fuente, J., Sander, P., Martínez-Vicente, J. M., Vera, M., Garzón, A., Fadda, S.: Combined effect of levels in personal self-regulation and regulatory teaching on meta- 
cognitive, on meta-motivational, and on academic achievement variables in undergraduate students. Frontiers in Psychology 8 (2017).

55. Gašević, D., Jovanović, J., Pardo, A., Dawson, S.: Detecting learning strategies with analytics: links with self-reported measures and academic performance. Journal of Learning Analytics 4(1) (2017).

56. Pardo, A., Martinez-Maldonado, R., Buckingham Shum, S., Schulte, J., McIntyre, S., Gašević, D., Gao, J., Siemens, G.: Connecting data with student support actions in a course: a hands-on tutorial. In: LAK '17 Proceedings of the Seventh International Learning Analytics \& Knowledge Conference, pp 522-523. (2017).

57. Pintrich, P., Smith, D., Garcia, T., Mckeachie, W.: Reliability and predictive validity of the Motivated Strategies for Learning Questionnaire (MSLQ). Educational and Psychological Measurement 53(3), 801-813 (1993). 